\title{
A mosaic infertile case of isodicentricY-chromosome with duplicated SRY, SHOX and deleted AZF locus
}

\author{
Ozturk Ozdemir*, Baris Paksoy, Taner Karakaya and Fatma Silan \\ Department of Medical Genetics, Faculty of Medicine, Canakkale Onsekiz Mart University, Turkey
}

\begin{abstract}
Objective: Structural Y chromosome abnormalities such as; DAZ, AZF and sY152 deletion play a key role in the genetic etiology of male infertility. Here we used comparable techniques to determine the characteristics of $Y$ chromosome microdeletions and/or duplications in an infertile man in the current report.

Methods: In the diagnosis of the current case, we used and compared different well optimised techniques such as; standard cytogenetic C and GTG banded karyotypes, flourescence in-situ hybridization (FISH), QF-PCR, a multiplex fragman PCR analysis for standarized of eigth sequence-tagged site (STS) and microarray comparative genomic hybridization $(\mathrm{aCGH})$ methods for detection of $\mathrm{Y}$ chromosome duplications and microdeletions.

Results: In the current thirty-year-old infertile male report, we present a detailed molecular-cytogenetic characterization of an individual with mosaicism involving an isodicentric $\mathrm{Y}$ chromosome and some phenotypic features. He was in tall stature, microtestis, delayed speech and increased gonadotropins (levels) [(FSH(20 miU/ $\mathrm{ml}, \mathrm{N}: 1.5-12,5), \mathrm{LH}(15.3 \mathrm{miU} / \mathrm{ml}, \mathrm{N}: 1.8-9)$ and prolactin $(15 \mathrm{ng} / \mathrm{ml}, \mathrm{N}: 4-16)]$ and azoospermia clinically. He was identified mos46,X,idic(Y)(pter->q12::q12->pter) $(92) / 45, \mathrm{X}(8)$ karyotype after comparable refine genetic methods. SRY, SHOX and amelogenin genes were duplicated and AZF, C band positive region of q arm were deleted in the current azoospermic male.
\end{abstract}

Conclusion: The comparable multiplex QF-PCR, karyotyping and microArray-CGH techniques are capable to detect all structural Y chromosome anomalies in diagnosis and prior to artificial reproduction techniques (ART) in male infertility.

\section{Introduction}

Numerical or structural chromosome abnormalities in tandem with mosaicism are observed in various phenotypic features from Turner syndrome to mixed gonadal dysgenesis to normal males $[1,2]$. These phenotypic features are observed in mosaic ones for $\mathrm{X}$ and secondline sex chromosome. Sex chromosomal abnormalities are present in $0.5 \%$ of live births. The dicentric chromosomal status is the most common structural abnormality of $\mathrm{Y}$ chromosome that determined in the mosaic karyotypes [3]. During the unstable conditions in dividing cells, the $\mathrm{Y}$ chromosome may disappear and resulting in the mosaic type state of 45,X chromosome [2,4]. Risk of developing gonadoblastoma increases in the presence of deviant $\mathrm{Y}$ chromosome structure in the individual with sex chromosome mosaicism. By the existence of deviant $\mathrm{Y}$ chromosome structure in the patient with mosaicism is associated with increasing risk of gonadoblastoma [4]. The risk of developing gonadoblastoma is more prevalent especially as age increases in patients with mixed gonadal dysgenesis [2]. Under normal circumstances, particular Y- linked genes play an important role in the diversion of embryonic development into male pathway. With the presence of these genes, the development of testis and the acquisition of normal male phenotype, even if karyotype 46, XX, is achieved; their absence lead to infertility in men [2]. The SRY gene is a transcription factor present in the short arm of the $\mathrm{Y}$ chromosome and has an essential role in the development of the testis.

Here we report detailed molecular-cytogenetic characterization of an infertile man with mosaic isodicentric $\mathrm{Y}$ chromosome structure and duplicated SRY, SHOX, amelogenin genes and deleted AZF, C band positive region of $\mathrm{q}$ arm in $\mathrm{Y}$ chromosome.

\section{Case report}

We reported a case of thirty-year-old infertile male patient with azoospermia. On examination, patient was described with tall stature, microtestis, delayed speech and increased gonadotropins levels [(FSH(20miU/ml, N:1.5-12,5), LH(15.3 miU/ml, N:1.8-9) and prolactin (15 ng/ml, N:4-16)]. He was diagnosed with various cytogenetic and molecular techniques. The diagnosis was established by (performing) cytogenetic karyotype analysis (GTG, NOR, C-banding), FISH, QFPCR and MicroArray-CGH(Agilent $60 \mathrm{~K}$ platform, US). Heparinized and blood-EDTA samples were used for lymphocyte culture and total genomic DNA isolation. Standart Trypsin-GTG banding was performed for karyotyping which was described according to the International System for Human Cytogenetic Nomenclature. When small metacentric Y chromosome was observed by GTG banding; It was suspected that this chromosome might have an abnormal structure was described isodicentric $\mathrm{Y}$ in this report shortly after. Some metaphyses showed aneuploidy of X chromosome. We detected either total deletion of the heterochromatic region of $\mathrm{Yq}$ and dicentric status of Y chromosome by C-band staining technique (Figure 1A). NOR

Correspondence to: Ozturk Ozdemır, Faculty of Medicine, Department of Medical Genetics, Canakkale Onsekiz Mart University, 17100, Canakkale, Turkey, Tel: +90 286 2180018/2107, E-mail: ozdemir615@yahoo.com

Key words: deleted AZF, duplicated SRY and SHOX, mosaic idicY chromosome, infertile man

Received: February 08, 2017; Accepted: March 09, 2017; Published: March 11, 2017 
A

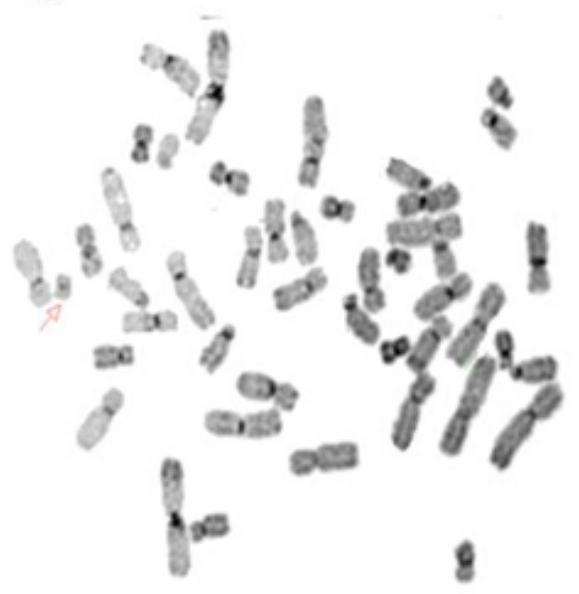

B

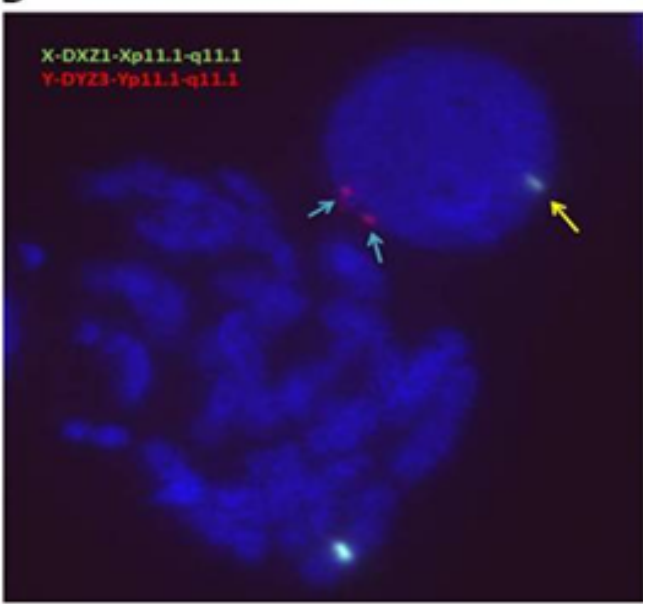

Figure 1. C -Banded and FISH profiles of methaphase and interphase cells from the proband. Case. Arrow indicate the C-banded $\mathrm{Y}$ chromosome in methacentric profile and without $\mathrm{C}$ band positive region (A). The blue arrows show dublicated SRY signals(red) and yellow arrow shows the X chromosome(Xq11, green), (B).

A

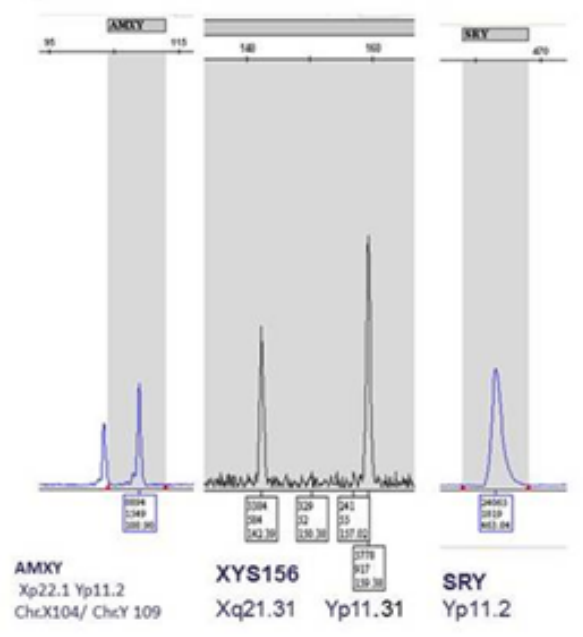

B

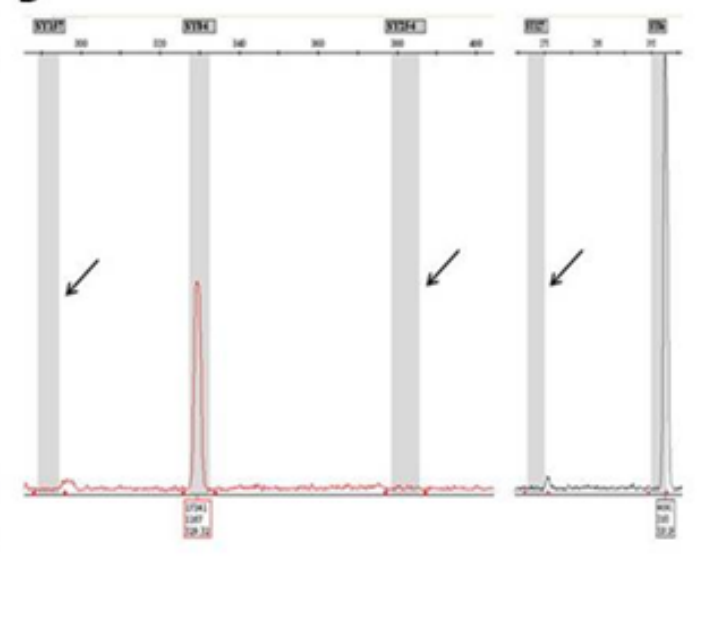

Figure 2. The QF-PCR profiles(A) and fragman analysis(B) of the DAZ gene region of the Y chromosome in the current infertile case. Shows the positive target of SRY, AMELY, SY86 and SY84 products but deleted the rest of SY152, SY153, SY134, RBMY, SY127, SY157, SY255 and SY254 locus (arrows) in the current proband case (B).

staining revealed no satellite regions which absence of the evidential sign for Y chromosome. FISH analysis for SHOX region was used for conformation structural integrity towards any aberration $\mathrm{p}$ arm of $\mathrm{Y}$ chromosome and determination of double signals for SRY (Figure 1B). The QF-PCR analysis was made for the identification of SRY gene and Amelogenin duplication on the chromosome $\mathrm{Y}$ (Figure 2A). AMEL-X/AMEL- Y ratio, suggesting a possibility of structural and or numerical sex chromosome anomalies. All the technical analysis above we mentioned were made for assay current case's karyotype status. On the basis of the clinical complaint of male infertility, we searched for long arm deletion including AZF b,c and d were detected with Y microdeletion analysis (Figure 2B). Genome-wide all chromosomes were also identified by Agilent SurePrint G3 Human CGH 60K MicroArray Platform (Agilent Technologies, CA, United States) chromosomal microarray analysis for the advance detection of affected gene or genes in the chromosomal break points for the presented case(Figure 3). After using of all comparable techniques the current infertile man wad diagnosed as mos46,X,idic(Y)(pter->q12::q12->pter) (92)/45,X(8).Some eigth sequence-tagged sites (STS) sY85, G34990,
sY133, sY127, sY254, sY255 were deleted after multiplex fragman PCR analysis (Figure $2 \mathrm{~B}$ ).

\section{Discussion}

Cytogenetic and molecular analysis results revealed that the most common structural change in $\mathrm{Y}$ chromosome is dicentric $\mathrm{Y}$ and monosomic 45,X cell line is frequently co-existence with dicentric chromosomes4. Sexual determination and clinical features depend on the rate of mosaicism in the patient's cell lines [1].

Many reports have been presented about mosaicism with $\mathrm{Y}$ chromosome in which patients clinical features from Turner syndrome, male or female disorder of sex development (DSD) to normal male development [5]. For accurate genetic counseling, entirely physical examination and scannig should be performed. When baby boy's karyotype result was $45, \mathrm{X} / 46, \mathrm{XY}$ mosaicism, even if his external genitelia normal, testes may be abnormal. When the male baby results in a karyotype of $45, \mathrm{X} / 46, \mathrm{XY}$ mosaicism, the testes may be abnormal even if the external genitalia is normal. Therefore, abdominal 


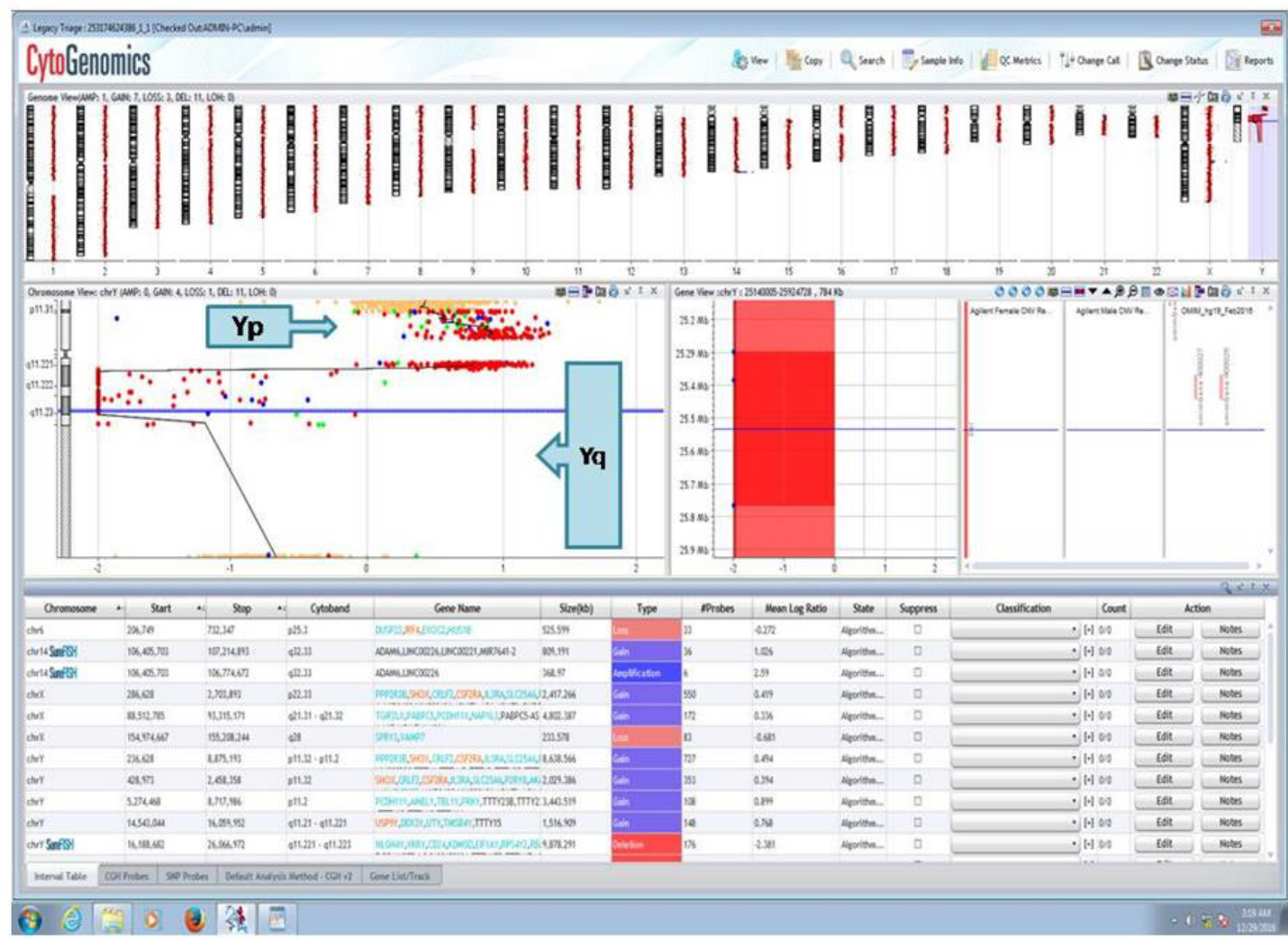

Figure 3. The MicroArray-CGH profiles revealed of Yp duplication and Yq deletion in the current infertile case with mos46,X,idic(Y)(pter->q12::q12->pter)(92)/45,X(8) karyotype.

ultrasonography and hormonal tests are needed. However, most male babies have normal testes with reduced fertility in the future [6].

Surgery may be performed for from minör genitalia abnormalities such as curved penis, hipospadias, crypthoorchidism to internal female tractus. However even so, internal female tract surgery is optional by virtue of they never cause any problem [6]. İsodicentric $\mathrm{Y}$ chromosome is assosiated with nonobstructive male infertility. This variation depends on mosaic cell line of $45, \mathrm{X}$ and also the percentage of SRY-positive cells in the gonads [7]. As a result, in the mosaic patient, dominant cell line seem to be influencing the sex phenotype irrespective of the proportion of the Y-cell line [8-10].

In conclusion, the current results showed us that comparable multiplex QF-PCR, karyotyping and microArray-CGH techniques are capable to detect all structural Y chromosome anomalies in diagnosis and prior to artificial reproduction techniques (ART) in male infertility.

\section{Acknowledgements}

Authors are very greatful for the current project that funded by scientific research and project supporting unit - BAP (Grant no: 277/2014), Canakkale Onsekiz Mart University, Canakkale, Turkey.

\section{References}

1. Kelly TE, Franko JB, Rogol A, Golden WL (1998) Discordant phenotypes and 45,X/46,X,idic(Y). J Med Genet 35: 862-864. [Crossref]

2. Al-Achkar W, Wafa A, Liehr T, Klein E, Moassass F (2012) Detailed analysis of an $\operatorname{idic}(\mathrm{Y})(\mathrm{q} 11.21)$ in a mosaic karyotype. Mol Med Rep 6: 293-296. [Crossref]

3. Torres TP, Rojas XB, Narváez MB, Montanero EL2, Sarasti AN (2015) Triplex Realtime Polymerase Chain Reaction Optimization for AZF Y-chromosome Microdeletion Analysis. JBRA Assist Reprod 19:37-43. [Crossref]
4. Caglayan AO, Demiryilmaz F, Kendirci M, Ozyazgan I, Akalin H, et al. (2009) Mixed gonadal dysgenesis with $45, \mathrm{X} / 46, \mathrm{X}, \operatorname{idic}(\mathrm{Y}) / 46, \mathrm{XY}, \operatorname{idic}(\mathrm{Y})$ karyotype. Genet Couns 20: 173-179. [Crossref]

5. Sangeetha R, Balachandar V, Devi SM, Velmurugan P, Kumar BL, et al. (2010) Cytogenetic study on sexual ambiguity in humans. Int J Hum Genet 10: 81-86.

6. Zhu Y, Wu T, Li G, Yin B, Liu H, et al. (2015) The sperm quality and clinical outcomes were not affected by sY152 deletion in Y chromosome for oligozoospermia or azoospermia men after ICSI treatment. Gene 573: 233-238.[Crossref]

7. Kalantari H, Asia S, Totonchi M, Vazirinasab H, Mansouri Z, et al. (2014) Delineating the association between isodicentric chromosome $\mathrm{Y}$ and infertility: a retrospective study. Fertil Steril 101: 1091-1096. [Crossref]

8. Zheng HY, Li Y, Shen FJ, Tong YQ (2014) A novel universal multiplex PCR improves detection of AZFc Y-chromosome microdeletions. J Assist Reprod Genet 31: 613-620. [Crossref]

9. Wiland E, Yatsenko AN, Kishore A, Stanczak H, Zdarta A, et al. (2015) FISH and array CGH characterization of de novo derivative $\mathrm{Y}$ chromosome (Yq duplication and partial Yp deletion) in an azoospermic male. Reprod Biomed Online 31: 217-224.[Crossref]

10. Premi S, Srivastava J, Panneer G, Ali S (2008) Startling mosaicism of the Y-chromosome and tandem duplication of the SRY and DAZ genes in patients with Turner Syndrome. PLoS One 3:e3796.[Crossref]

Copyright: (C2017 Ozdemir O. This is an open-access article distributed under the terms of the Creative Commons Attribution License, which permits unrestricted use, distribution, and reproduction in any medium, provided the original author and source are credited. 